\title{
KOMODIFIKASI DAN MAKNA SIMBOLIK MOTIF TENUN MUNA SEBAGAII BENTUK KEARIFAN LOKAL MASYARAKAT KABUPATEN MUNA
}

\author{
Oleh:
}

\author{
Wa Ode Lusianai ${ }^{1}$, Aryuni Salpiana Jabar ${ }^{2}$, Ikrima Nurfikria ${ }^{3}$, Sitti Hairani Idrus ${ }^{4}$ \\ Dosen Ilmu Komunikasi ${ }^{1}$, Dosen Sosiologi ${ }^{2}$, Dosen Jurnalistik ${ }^{3}$, Dosen Administrasi Bisnis ${ }^{4}$ Universitas Halu Oleo \\ lusianaiwaode@uho.ac.id
}

\begin{abstract}
Local weaving is the identity and wealth inherent in some area. Muna Regency, Southeast Sulawesi, is known to have regional weaving with diverse and interesting qualities and motits. There are many previous Muna weaving motits such as dhalima, samasili, panino toghe, bhotu, bhia-bhia, ledha, finda ngkonini, mango-manggopa, lante-lante, kambheano bhanggai, tibha-tibha, kaholeno ghunteli, kambhampu, bharalu, kasokasopa. To balance the development of the fashion industry, through the creative ideas of weavers, Muna's weaving motits undergo commodification called a series of motits. The visual of the first Muna weaving and Muna weaving produced by commodification and also the symbolic meaning of Muna woven motits as a result of commodification became a problem in this study. Located in Masalili Village, Muna Regency, researchers conducted observations and direct interviews with research informants. By using the qualitative descriptive analysis of Milles and Huberman's interactive model, it was found that from the visuals of Muna's weaving motifs, after experiencing commodification, the latest motifs have been produced. Whether it's a combination of samasili and butterfly motifs, samasili and kites and other types of motits. The development of the commodification motif has its own symbolic meaning. It describes regional identity, cultural preservation, openness with progress, diversity, and describes the value of local wisdom in integrating outside cultural elements into the development of the Muna weaving motif.
\end{abstract}

Keywords : commodification; symbolic meaning; local wisdom; Muna weaving.

\section{PENDAHULUAN}

Penelitian ini dititikberatkan pada perkembangan motif tenun Muna melalui visual tenun Muna dahulu hingga tenun Muna hasil komodifikasi serta makna simbolik dari tenun Muna hasil komodifikasi. Dalam perkembangannya, tenun Muna dahulu terdiri atas kurang lebi 15 motif diantaranya; bharalo, samasili, panino toghe, bhotu, bhia-bhia, ledha, finda ngkonini, mango-manggopa, dhadha lima, lante-lante, jhalima, gununggunung, kambheano bhanggai, kaparanggigi, katamba ghawu, kapododo, kaburino, kaso-kasopa. Selain motifmotif tersebut untuk mengimbangi perkembangan kebutuhan pasar, maka motif tersebut kini ada yang dimodifikasi yang disebut dengan rangkaian motif.

Perkembangan dunia fashion melalui hadirnya budaya luar di tengah-tengah adat-istiadat, budaya, mendorong tumbuhnya komodifikasi rangkaian motif tenun Muna.

Sudikan (2013) menyebutnya sebagai kecerdasan lokal (local genius), dan pengetahuan lokal (local knowledge) dalam menyelamatkan lingkungan, serta pelaksanaan nilai-nilai tersebut oleh masyarakat sebagai kearifan lokal (local wisdom). Ide kreatif ini menjadi landasan komodifikasi motif dan makna pada tenun Muna sehingga melahirkan rangkaian motif yang mampu menembus pasar global.

Kain tenun Muna sebagai bentuk pelestarian kearifan lokal dan identitas bangsa menyiratkan makna pada setiap rangkaian motif yang dihasilkan oleh penenun. Komodifikasi tenun dilakukan tanpa meninggalkan nilai 
lokal dari filosofi tenun Muna dengan mengedepankan nilai komersial. Proses komodifikasi motif dan makna dengan mengolaborasi kepentingan industri dan budaya fashion dengan pertimbangan adat istiadat, sosial, budaya dan ekonomi masyarakat. Komodifikasi motif dan makna simbolik pada motif tumbuh dari kedua kepentingan tersebut menggeser nilai-nilai sakral penggunaan tenun Muna menjadi sekuler.

Penelitian ini mengkaji tentang komodifikasi motif tenun Muna dalam menghadapi perkembangan industry fashion dan makna simbolik motif tenun Muna sebelum dan sesudah mengalami komodifikasi sebagai bentuk kearifan lokal. Hal ini dimaksudkan untuk mengimbangi peningkatan selera pemakaian kain adat tenun Muna dengan pemahaman makna motif dan penggunaannya dikalangan masyarakat.

\section{METODE PENELITIAN}

Penelitian ini menggunakan metode kualitatif. Penelitian kualitatif ditujukan untuk mendeskripsikan dan menganalisis fenomena, peristiwa, aktivitas social, sikap, kepercayaan, persepsi dan pemikiran manusia secara individu maupun kelompok (Ghony:2012). Penelitian kualitatif digunakan untuk mendeskripsikan makna simbolik pada motif tenun Muna sebagai bentuk kearifan lokal daerah Kabupaten Muna. Proses penelitian dilaksanakan di desa penenun yang ada di Kabupaten Muna dengan membuat catatan data, foto, informasi yang dilihat dan didengar serta dianalisis dan ditafsirkan ragam dan makna motif kain tenun Muna.

\section{PEMBAHASAN}

\section{A. Visual Tenun Muna Terdahulu Sebelum Mengalami Komodifikasi}

1. Motif Dhalima, tenunan ini digunakan pada acara adat perkawinan. Khusus digunakan kaum bangsawan laki-laki dan peremuan.

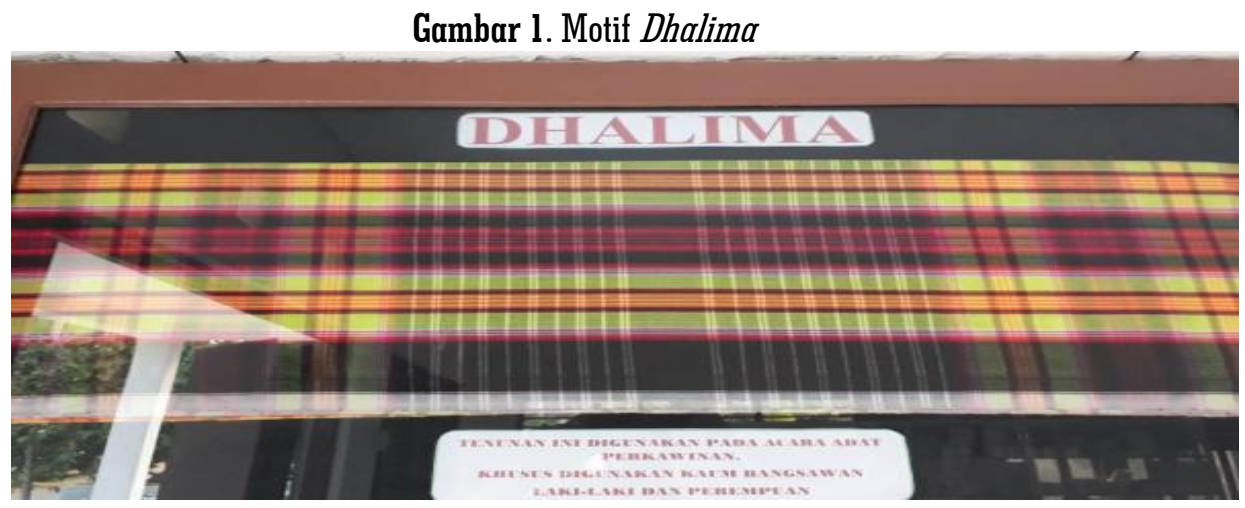

(Sumber : Bumdes Desa Masalili)

2. Motif Samasili, tenunan ini digunakan pada acara adat pernikahan kalangan bangsawan laki-laki dan perempuan.

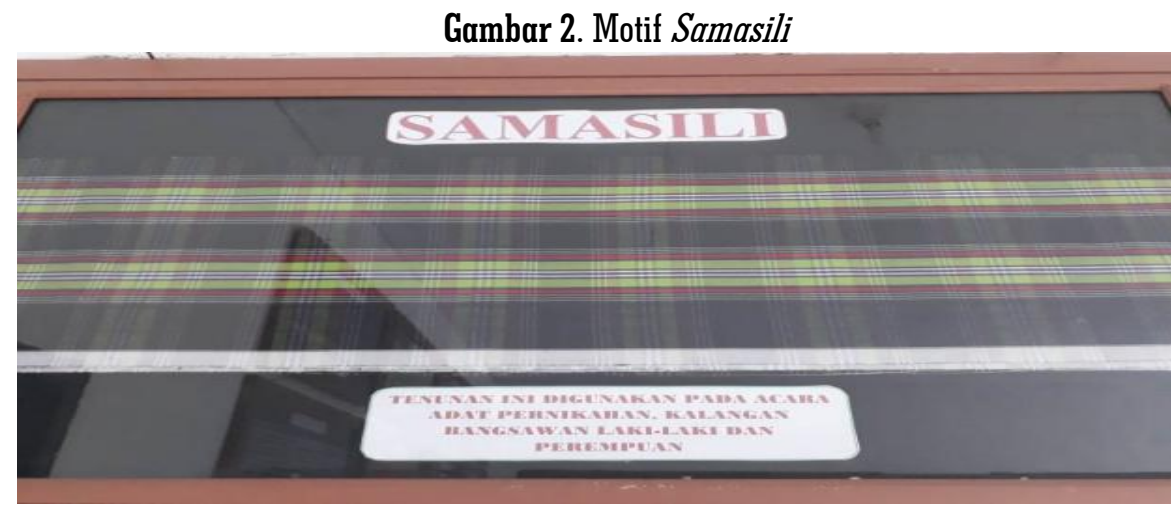

(Sumber : Bumdes Desa Masalili) 
Vol.2 No.2. July 2019. pp.52-64. Copyright@2019 Journal PUBLICUHO Faculty of Social and Political Sciences Halu Oleo University, Kendari, Southeast Sulawesi, Indonesia. e-ISSN: 2621-1351. Open Access at:

http://ojs.uho.ac.id/index.php/PUBLICUHO

Jounal publiuho is licensed under a Creative Commons Attribution 4.0 International License, which permits
unrestricted use, distribution, and reproduction in any medium, provided the original work is properly cited.

3. Motif Panino Toghe, tenunan ini digunakan oleh kalangan masyarakat umum, digunakan untuk shalat atau tidur.

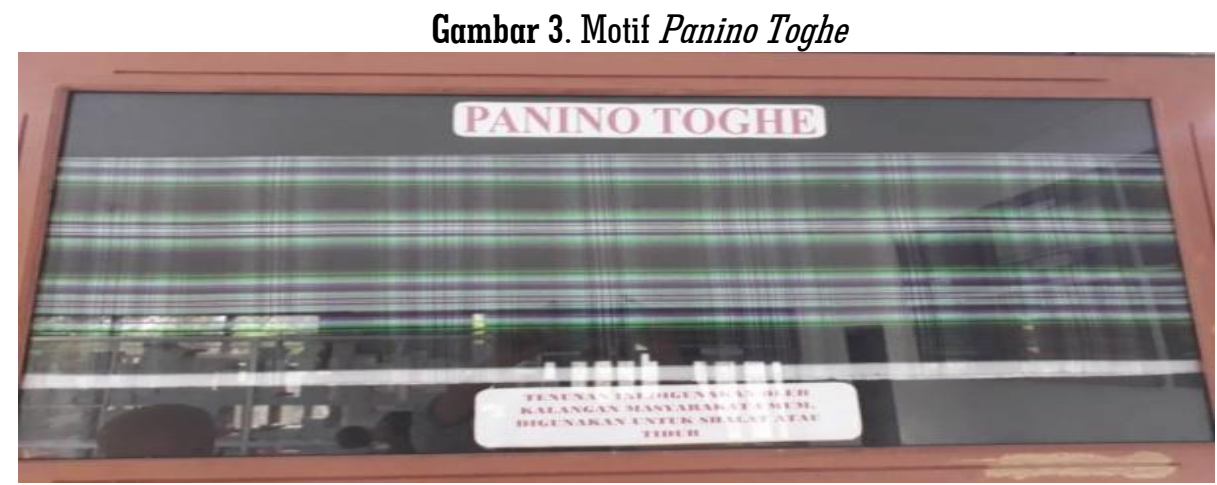

(Sumber : Bumdes Desa Masalili)

4. Motif $B h o t u$, tenunan ini digunakan oleh kaum bangsawan pada acara adat seperti perkawinan.

Gambar 4. Motif Bhotu

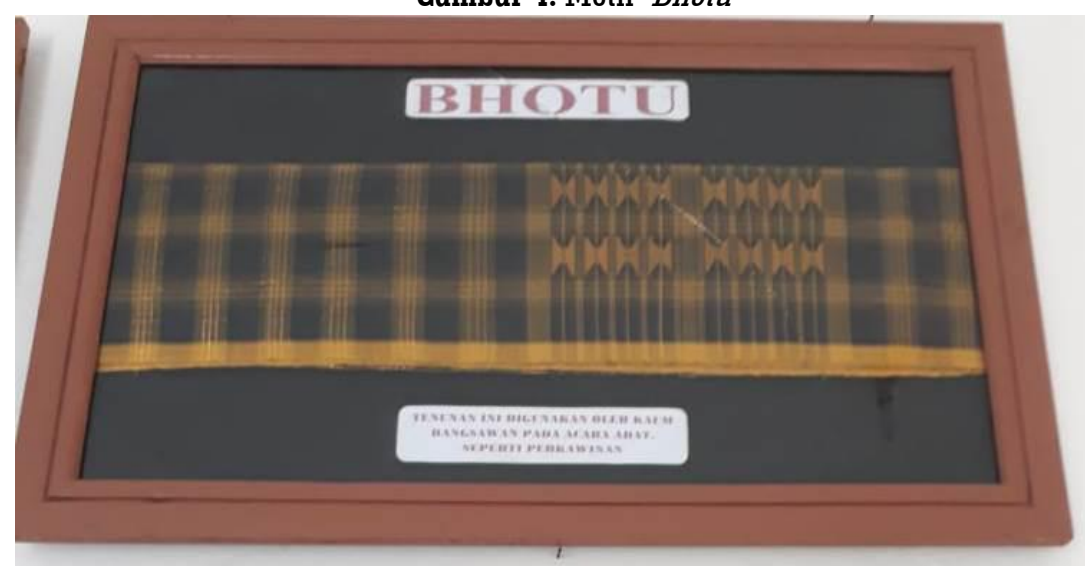

(Sumber : Bumdes Desa Masalili)

5. Motif Findangkonini, tenunan ini digunakan oleh remaja saat mencari jodoh (Dekamata)

Gambar 5. Motif Findangkonini

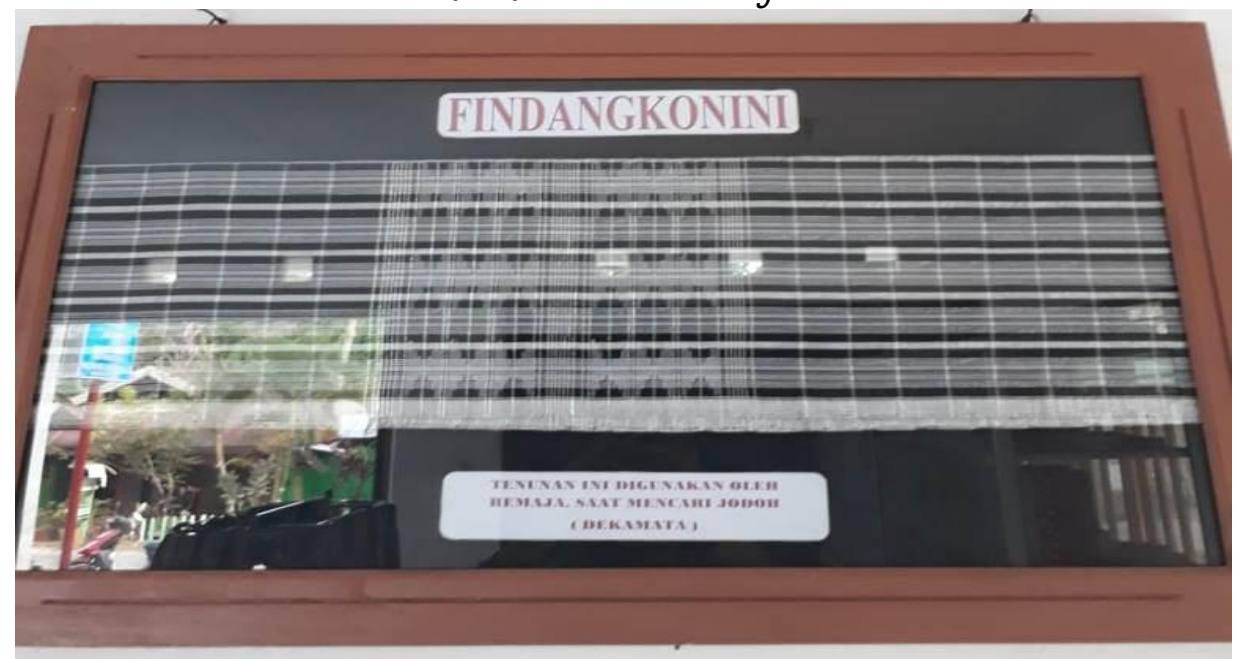

(Sumber : Bumdes Desa Masalili) 
Vol.2 No.2. July 2019. pp.52-64. Copyright@2019 Journal PUBLICUHO Faculty of Social and Political Sciences Halu Oleo University, Kendari, Southeast Sulawesi, Indonesia. e-ISSN: 2621-1351.Open Access at:

http://ojs.uho.ac.id/index.php/PUBLICUHO

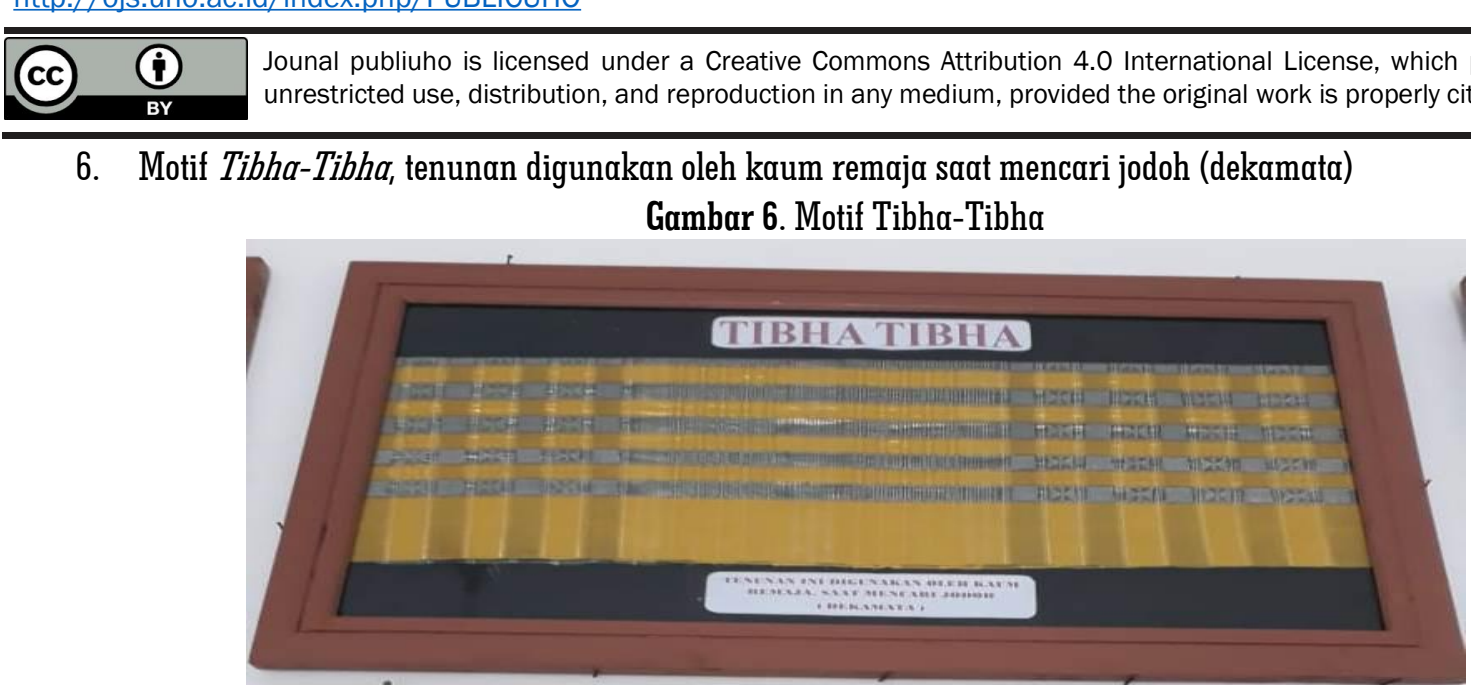

(Sumber : Bumdes Desa Masalili)

7. Motif Kambeano Banggai, tenunan ini digunakan oleh kalangan masyarakat umum, digunakan untuk shalat atau tidur.

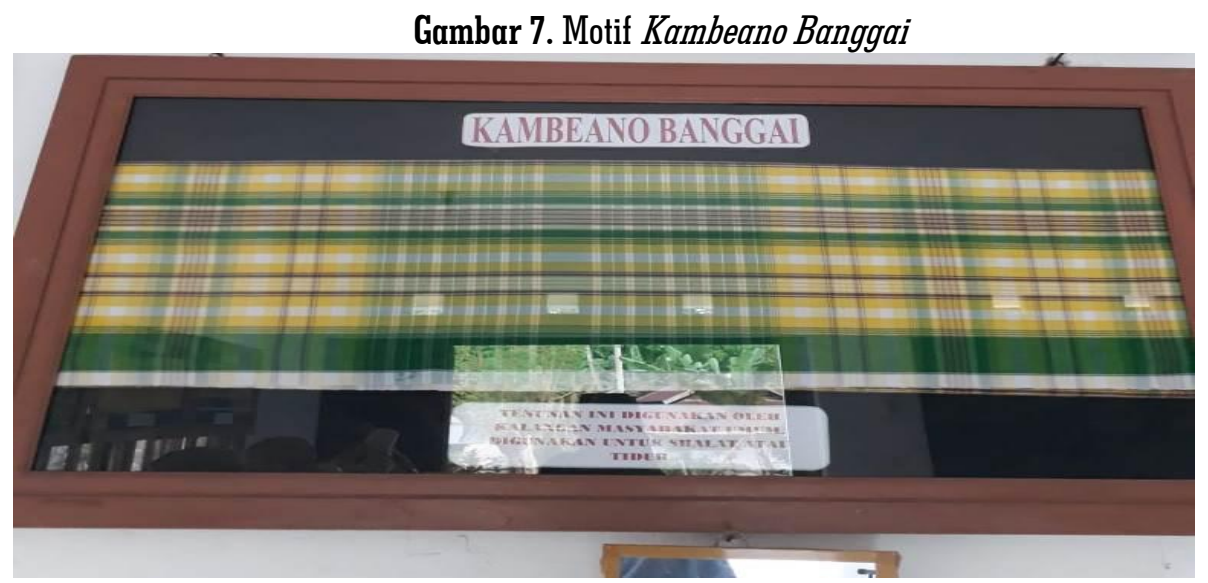

(Sumber : Bumdes Desa Masalili)

8. Motif Lante-Lante, tenunan ini digunakan oleh remaja saat mencari jodoh (dekamata).

Gambar 8. Motif Lante-Lante

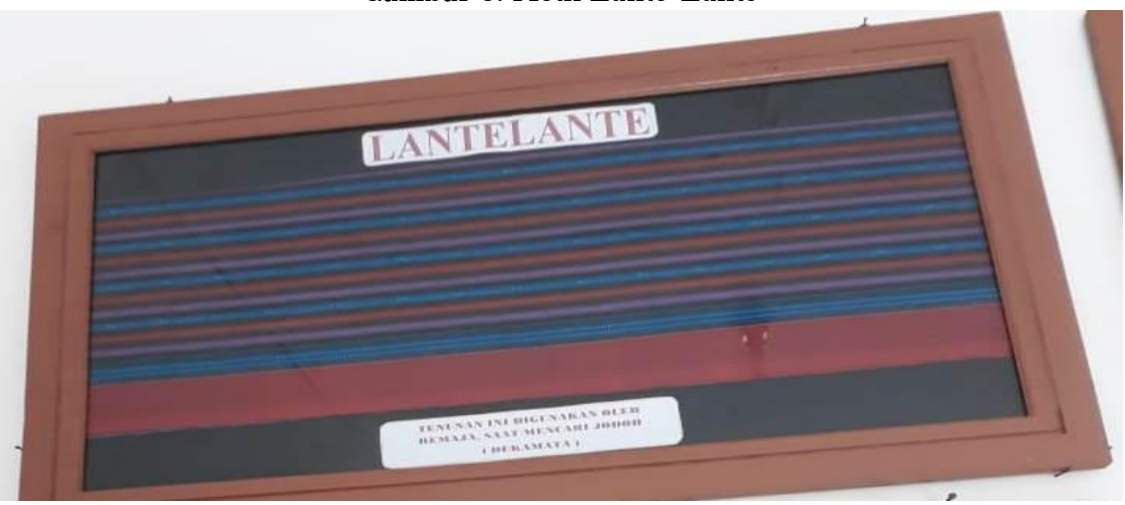

(Sumber : Bumdes Desa Masalili) 
Vol.2 No.2. July 2019. pp.52-64. Copyright@2019 Journal PUBLICUHO Faculty of Social and Political Sciences Halu Oleo University, Kendari, Southeast Sulawesi, Indonesia. e-ISSN: 2621-1351. Open Access at:

http://ojs.uho.ac.id/index.php/PUBLICUHO

Jounal publiuho is licensed under a Creative Commons Attribution 4.0 International License, which permits
unrestricted use, distribution, and reproduction in any medium, provided the original work is properly cited.

9. Motif Ledha, tenunan ini digunakan oleh masyarakat umum.

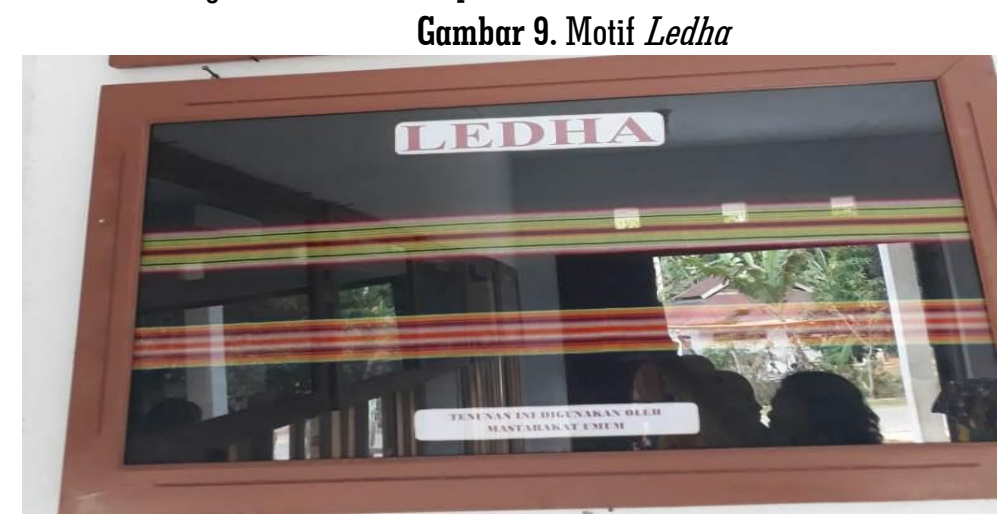

(Sumber : Bumdes Desa Masalili)

10. Motif Kaholeno Ghunteli, tenunan ini digunakan oleh kalangan masyarakat umum, digunakan untuk shalat atau tidur

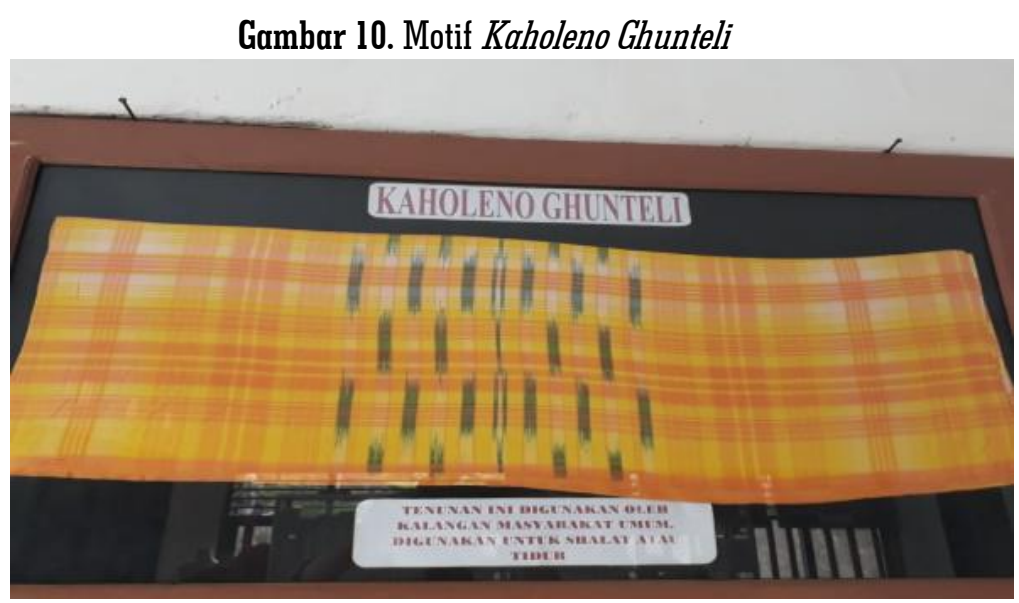

(Sumber : Bumdes Desa Masalili)

11. Motif Kambampu, tenunan ini digunakan oleh kalangan masyarakat pada umumnya digunakan untuk shalat atau tidur

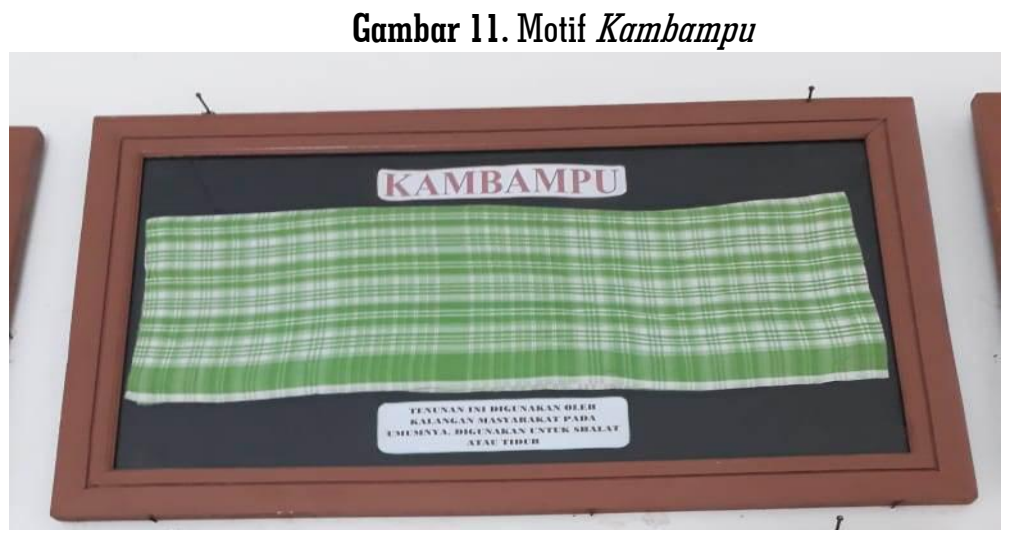

(Sumber : Bumdes Desa Masalili) 
Vol.2 No.2. July 2019. pp.52-64. Copyright@2019 Journal PUBLICUHO Faculty of Social and Political Sciences Halu Oleo University, Kendari, Southeast Sulawesi, Indonesia. e-ISSN: 2621-1351.Open Access at:

http://ojs.uho.ac.id/index.php/PUBLICUHO

(C) Jounal publiuho is licensed under a Creative Commons Attribution 4.0 International License, which permits

12. Motif Bhia-Bhia, tenunan ini khusus digunakan oleh anak remaja putri (perempuan yang belum menikah)

Gambar 12. Gambar Bhia-Bhia

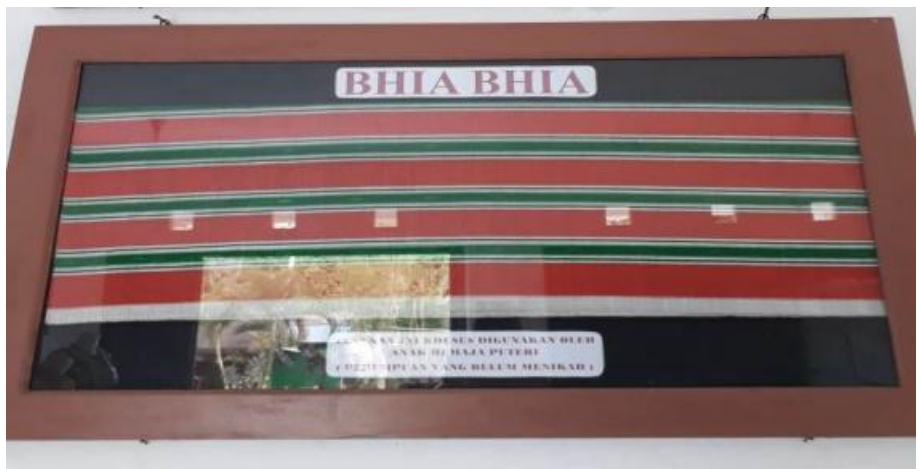

(Sumber : Bumdes Desa Masalili

13. Motif Bharalu, tenunan ini digunakan oleh tokoh adat (kaomu)

Gambar 13. Motif Bharalu

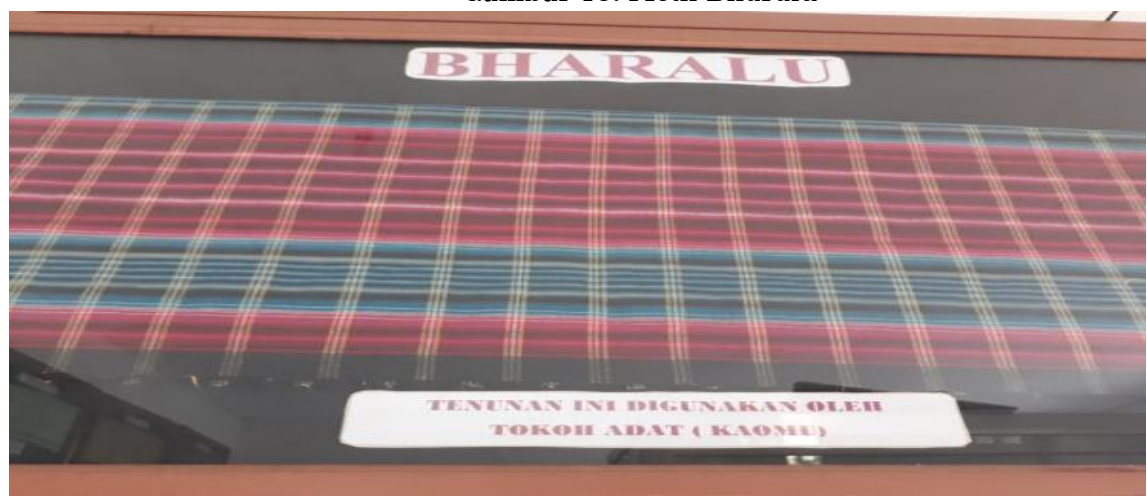

(Sumber : Bumdes Desa Masalili)

14. Motif Manggo-Manggopa, tenunan ini digunakan

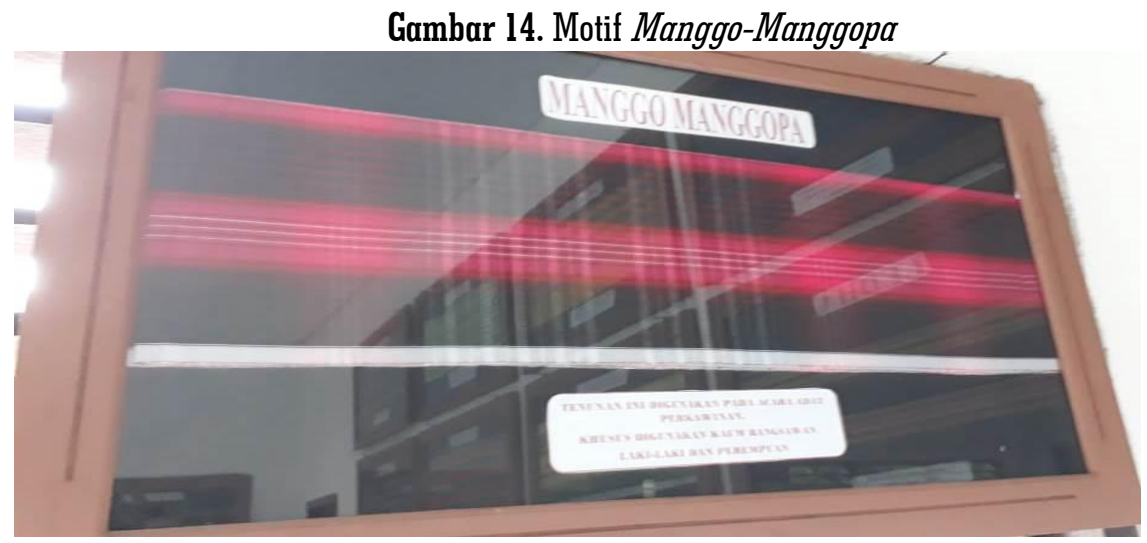

(Sumber : Bumdes Desa Masalili) 
Vol.2 No.2. July 2019. pp.52-64. Copyright@2019 Journal PUBLICUHO Faculty of Social and Political Sciences Halu Oleo University, Kendari, Southeast Sulawesi, Indonesia. e-ISSN: 2621-1351. Open Access at:

Jounal publiuho is licensed under a Creative Commons Attribution 4.0 International License, which permits
unrestricted use, distribution, and reproduction in any medium, provided the original work is properly cited.

15. Motif Kasokasopa, tenunan ini digunakan oleh remaja saat mencari jodoh (dekamata).

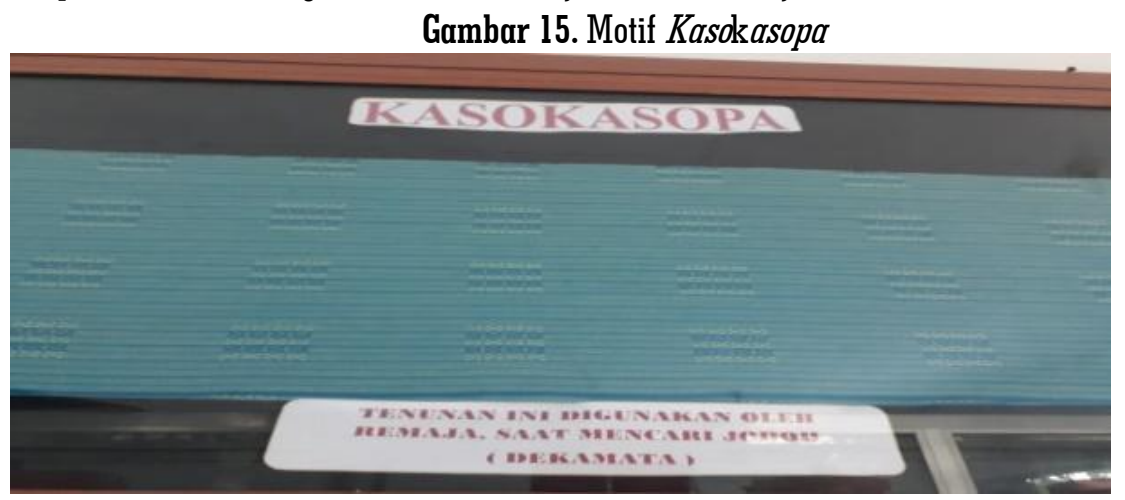

(Sumber : Bumdes Desa Masalili)

Visual motif tersebut dengan semakin berkembangan trand fashion maka mengalami komodifikasi motif. Namun demikian tidak semua motif mengalami komodifikasi oleh penenun. Beberapa motif yang telah mengalami komodifikasi namun tetap mempertahankan ciri khas dari motif sebelumnya seperti motif samasilimotif yang mengalami komodfikasi disebut rangkaian motif. Rangkaian motif oleh setiap penenun berbeda-beda penyebutannya.

Proses komodifikasi motif tenun merupakan kreatifitas dari setiap penenun yang terinspirasi dari lingkungan dan keadaan sekitarnya. Setiap penenun akan menghasilkan rangkaian motif yang berbeda sesuai dengan daya kreatifitasnya. Setiap rangkaian motif yang dihasilkan, antara penenun sebisa mungkin untuk tidak meniru hasil komodifikasi motif penenun lainnya. Untuk itu, banyak penenun yang tidak mengizinkan hasil tenunannya di dokumentasikan untuk menghindari terjadinya "pencurian" motif.

Rangkaian motif dihasilkan dari proses komodifikasi dari tenun terdahulu dengan aneka motif. Aneka motif ini oleh setiap penenun memiliki penyebutan yang berbeda. Namun demikian, aneka motif tersebut menggambarkan keadaan lingkungan sekitar seperti kupu-kupu, layang-layang, bukit, bunga, serta motif bebas yang tidak mewakili benda apapun hanya karena tercipta dari ide kreatif penenun. Berikut beberapa visual komodifikasi rangkaian motif:

1. Rangkaian motif samasili dan layang-layang. Rangkaian motif jenis ini merupakan perpaduan antara motif tenun Muna samasili dengan rangkaian motif hasil komodifikasi. Penempatan rangkaian motif layang-layang tergantung pada kreatifitas penenun yang menciptakan motif tersebut dengan tidak menghilangkan unsur motif Muna terdahulu yaitu samasili. Berikut ini ada beberapa rangkaian motif dari perpaduan motif tenun Muna samasili dan laying-layang :

Gambar 16. Rangkaian Motif Samasili dengan Layang-Layang dan Motif Bebeas

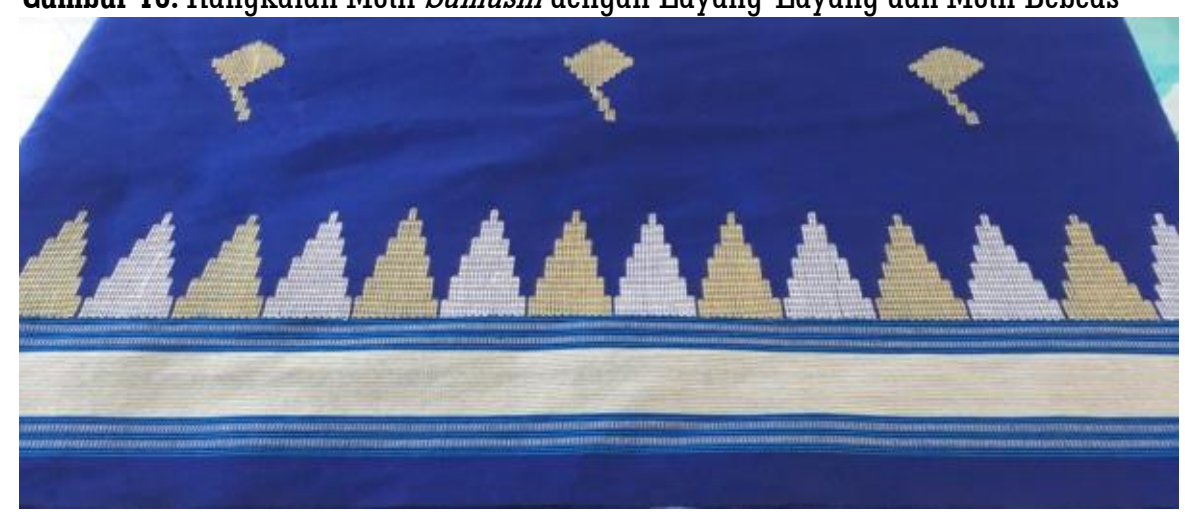

(Sumber : Dokumentasi peneliti) 
Vol.2 No.2. July 2019. pp.52-64. Copyright@2019 Journal PUBLICUHO Faculty of Social and Political Sciences Halu Oleo University, Kendari, Southeast Sulawesi, Indonesia. e-ISSN: 2621-1351.Open Access at:

http://ojs.uho.ac.id/index.php/PUBLICUHO

2. Rangkaian motif samasili dan kupu-kupu. Rangkaian motif jenis ini juga merupakan perpaduan motif Muna terdahulu samasili dengan motif kupu-kupu. Rangkaian motif yang dihasilkan oleh penenun yang menciptakan motif ini akan menghasilkan aneka hasil tenun dengan rangakain motif kupu-kupu. Memadukan beberapa rangkaian motif dalam sebuah hasil karya menjadi sebuah kreativitas yang mutlak dimiliki oleh masyarakat penenun di Desa Masalili. Berikut salah satu contoh rangkaian motif kupu-kupu :

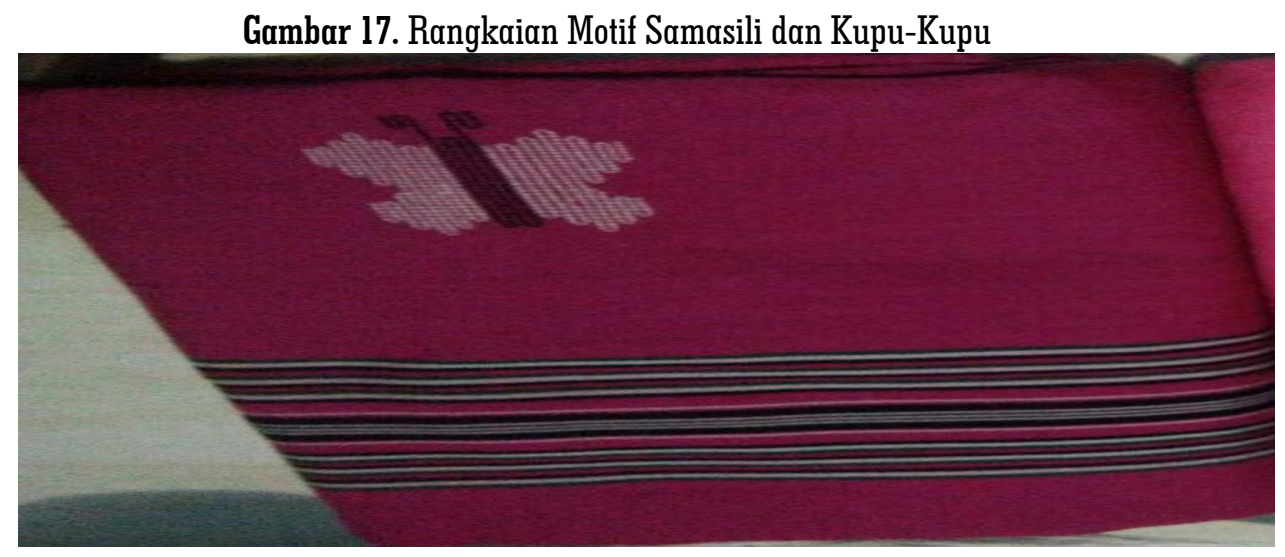

(Sumber : Dokumentasi peneliti)

3. Rangkaian motif samasili dengan motif bukit. Rangkaian motif jenis ini dijual dengan harga lebih mahal disbanding dengan rangkaian motif laying-layang dan kupu-kupu. Perbedaan harga jual atas rangkaian motif yang dihasilkan berdasarkan pada tingkat kesulitas pembuatan motif tersebut. Semakin sulit pembuatan rangkaian motifnya maka akan semakin tinggi pula harga jualnya. Berikut contoh rangkaian motifnya :

Gambar 18. Rangkaian Motif Samasili dengan Bukit dan Motif Bebas

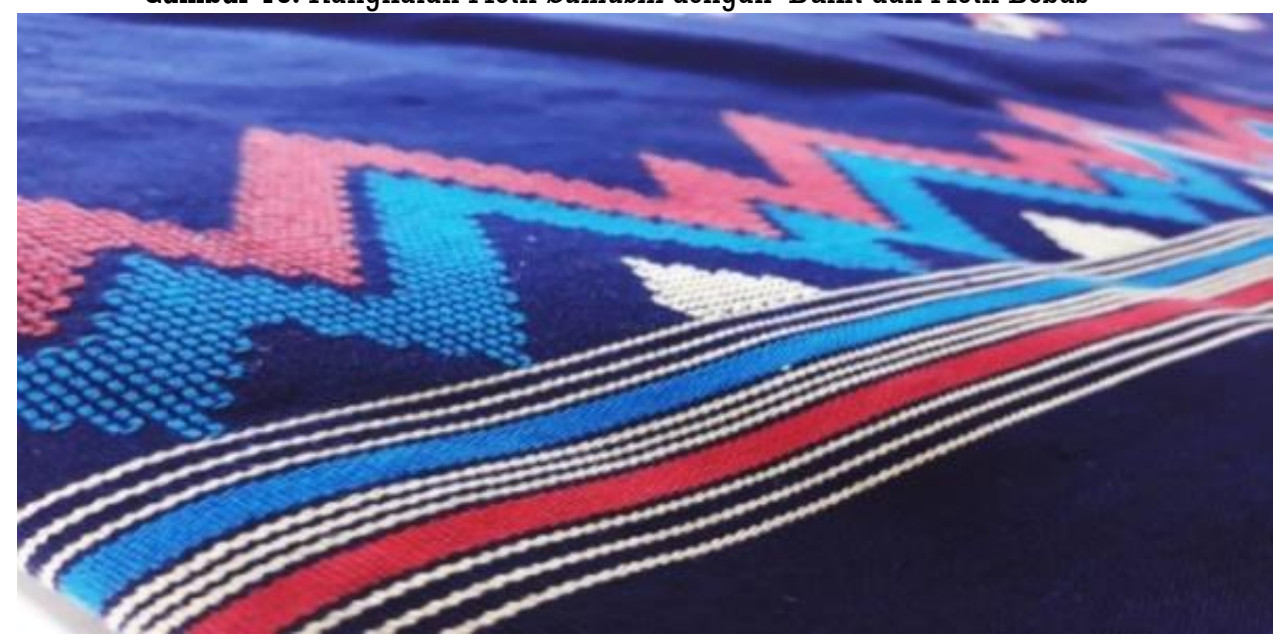

(Sumber : Dokumentasi peneliti)

4. Rangkaian motif samasili dengan motif bebas. Rangkaian motif jenis ini sekan tidak nampak dari kejauhan, tidak menggambarkan ikon atau benda apapun sehingga dikatakan sebagai motif bebas. Namun demikian, setiap rangkaian motif yang dihasilkan oleh penenun memiliki penyebutan yang berbeda-beda sehingga dilakukan pemberian nama secara umum dengan menggambarkan identitas motif. Jenis motif ini merupakan yang paling murah dari rangkaian motif lainnya karena pembuatan motifnya yang tidak terlalu sulit. Berikut contohnya : 
Vol.2 No.2. July 2019. pp.52-64. Copyright@2019 Journal PUBLICUHO Faculty of Social and Political Sciences Halu Oleo University, Kendari, Southeast Sulawesi, Indonesia. e-ISSN: 2621-1351. Open Access at:

Jounal publiuho is licensed under a Creative Commons Attribution 4.0 International License, which permits
unrestricted use, distribution, and reproduction in any medium, provided the original work is properly cited.

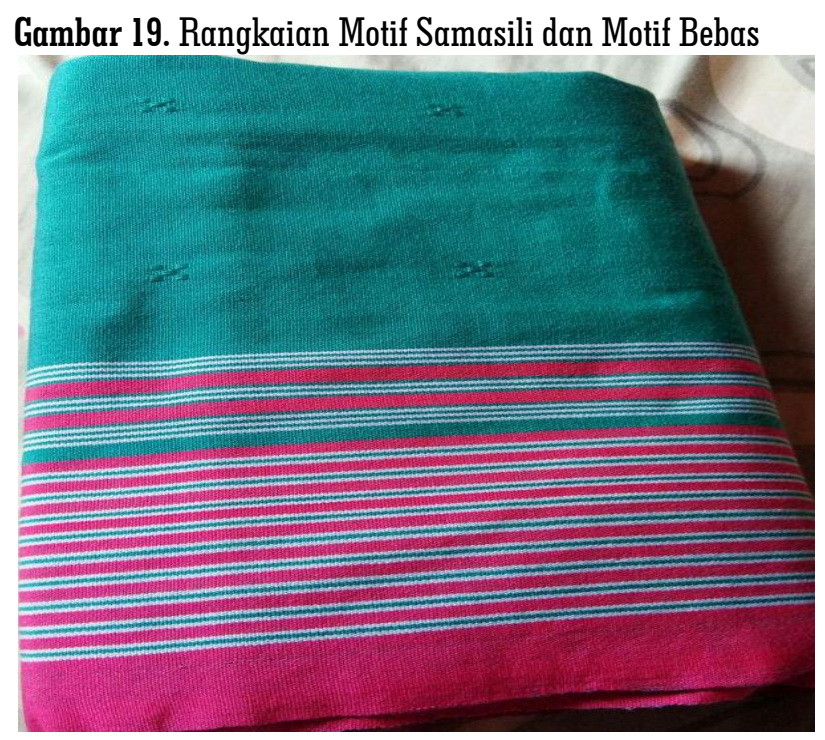

(Sumber : Dokumentasi peneliti)

Rangkaian motif tersebut oleh setiap penenun memiliki sebutan yang berbeda. rangkaian motif yang dihasilkan oleh setiap penenun pun berbeda-beda. Misalnya rangkaian motif tenun layang-layang, oleh sebagian penenun menyebutnya dengan sebutan sobi, kabunga lima dll. Rangkaian motif bebas seperti motif polos oleh sebagian penenun disebut motif leko. Rangkaian motif bebas dan bukit oleh sebagian penenun biasa disebut dengan motif leko. Butuh ketekunan dan kreatifitas penenun untuk menghasilkan sebuah rangkaian motif yang menarik dan bernilai jual tinggi. Semakin menarik dan sulit rangkaian motif yang dihasilkan maka akan semakin tinggi pula nilai jualnya.

Berbagai visual motif komodifikasi tersebut penggunaanpun telah berubah. Jika dulu tenun Muna hanya digunakan sebagai sarung adat, sarung shalat, ataupun sarung untuk tidur maka setelah mengalami komodifikasi motif telah bergeser penggunaannya yakni tidak hanya untuk peruntukan tersebut tetapi lebih banyal digunakan sebagai baju. Motif-motif hasil komodifikasi banyak digunakan untuk kebutuhan fashion. Mulai dari baju kantor, baju santai hingga baju pesta, hingga digunakaan pada acara-acara fashion show. Tidak hanya itu, komodifikasi tenun Muna banyak digunakan sebagai syall, kampurui, tas, taplak meja, bross. Selain desain motif yang menarik, komodfikasi tenun Muna juga terjadi pada perpaduan berbagai warna dalam sebuah tenunan. Berikut Visual pemanfaatan tenun Muna rangkaian motif komodifikasi :

1. Syall

Gambar 20. Syall

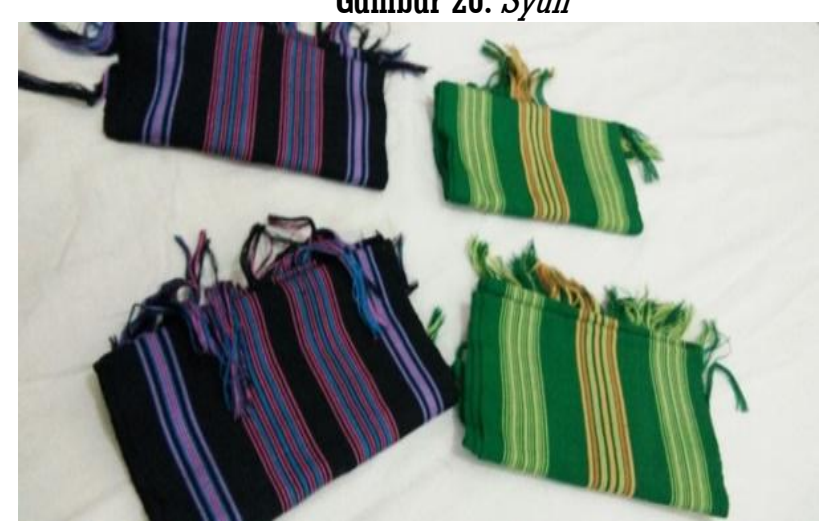

(Sumber : Dokumentasi peneliti) 
19

Vol.2 No.2. July 2019. pp.52-64. Copyright@2019 Journal PUBLICUHO Faculty of Social and Political Sciences Halu Oleo University, Kendari, Southeast Sulawesi, Indonesia. e-ISSN: 2621-1351.Open Access at:

http://ojs.uho.ac.id/index.php/PUBLICUHO

(C) Jounal publiuho is licensed under a Creative Commons Attribution 4.0 International License, which permits
unrestricted use, distribution, and reproduction in any medium, provided the original work is properly cited.

\section{Kampurui}

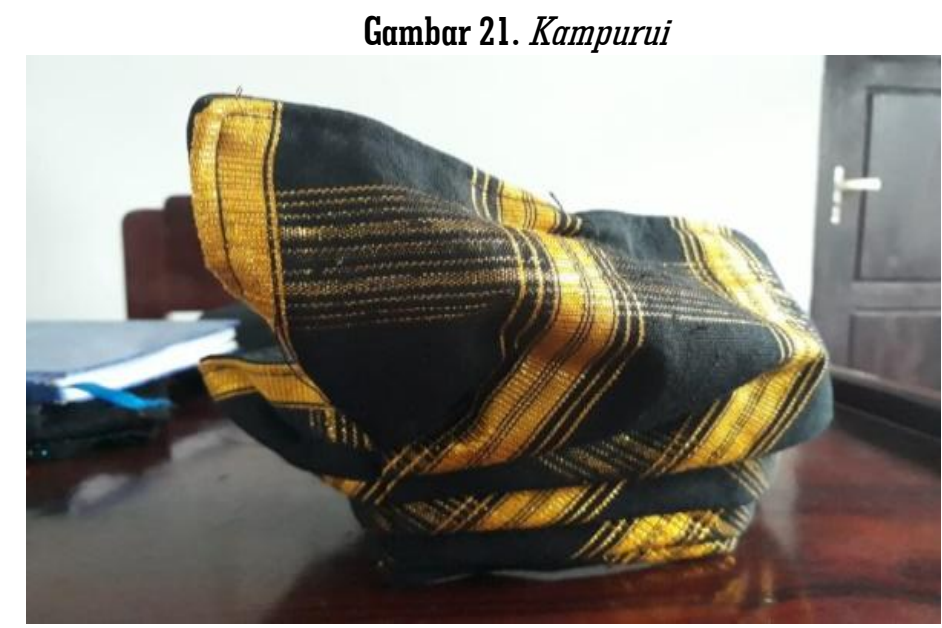

(Sumber : Dokumentasi peneliti)

3. Tas

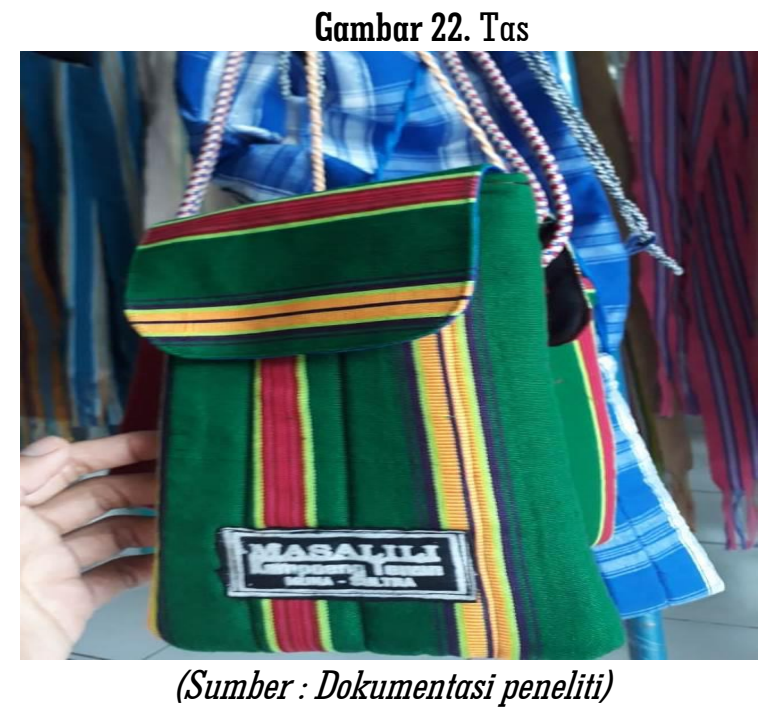

4. Taplak Meja

Gambar 23. Taplak Meja

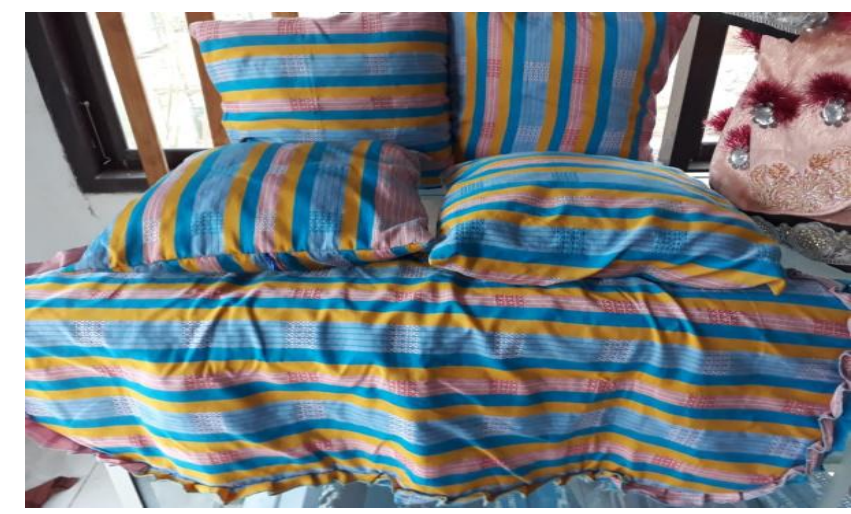

(Sumber : Dokumentasi peneliti)

|Journal Publicuho-Vol 2. No.2-2019 | 


JCunal publiuho is licensed under a Creative Commons Attribution 4.0 International License, which permits
unrestricted use, distribution, and reproduction in any medium, provided the original work is properly cited.

\section{Bross}

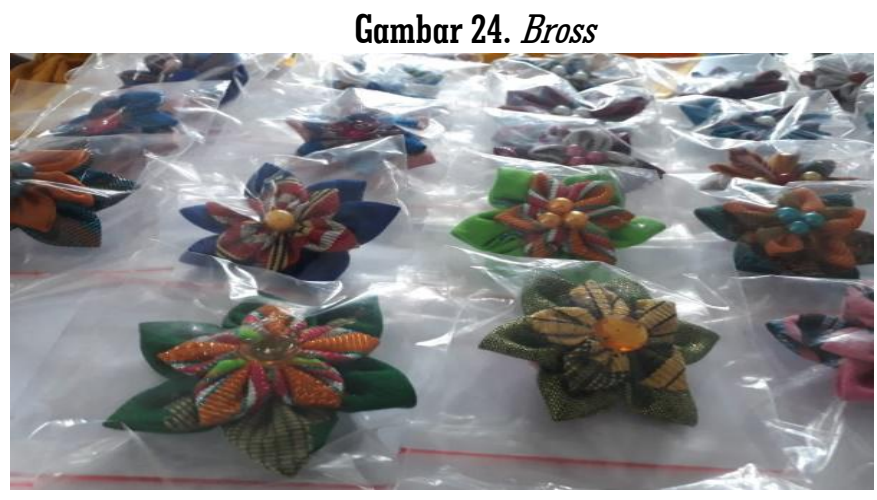

(Sumber : Dokumentasi peneliti)

Permainan warna pada tenun Muna sejak dahulu hingga kini masih terus bervariasi. Tenun Muna tidak hanya dikenal dengan aneka motifnya namun juga perpaduan warna atas setiap rangkaian motif yang dihasilkan pada sehelai tenun.

\section{B. Makna Simbolik Motif Tenun Muna Hasil Komodifikasi}

Mengkaji makna simbolik motif tenun Muna sejatinya mengkaji tenun Muna dalam perspektif fenomenologis, teknik pembuatannya, bahannya, motif dan penggunaannya, serta perkembangan motif tenun Muna hingga saat ini. Pembuatan tenun Muna masih dilakukan secara manual meski beberapa sudah ada yang menggunakan mesin. Namun demikian, di Desa Masalili masyarakat penenun mayoritas melakukan teknik menenun secara manual. Keindahan dan keunikan motif tenun yang hasilkan turut ditentukan oleh keuletan dan sisi estetika penenun. Tingkat kesulitan motif sejalan dengan harga dari tenun yang dihasilkan. Proses menenun ini dilakukan seorang diri.

Tenun Muna selain mengalami komodifikasi motif juga mengalami komodifikasi makna dari sesuatu yang bernilai sakral menuju sesuatu yang bernilai sekular. Artinya bahwa telah terjadi pergeseran dalam makna penggunaan dari tenun muna. Dahulu penggunaan tenun seakan sakral dalam ritual-ritual adat, keagaaman maupun acara budaya. Namun kini, penggunaannya telah banyak terlihat diruang-ruang kerja, suasana santai, menghadiri pesta. Tenun Muna kini telah masuk dalam arena fashion masyarakat. Telah terjadi pergeseran penggunaan tenun Muna dikalangan masyarakat.

Motif komodifikasi tenun Muna yang dilhami dari keadaan sekitar masyarakat yang dituangkan dalam berbagai bentuk desain motif. Berikut makna-makna simbolis yang terkandung dalam motif maupun warna hasil komodifikasi tenun Muna adalah sebagai berikut:

1. Menggambarkan Identitas daerah. Salah satu motif komodifikasi adalah motif layang-layang. Desain motif layang-layang yang ada dalam rangkaian motif tenun Muna menggambarkan pelestarian nilai kaerifan lokal dalam konteks pelestarian nilai sejarah bahwa layang-layang tertua ada di Kabupaten Muna..

2. Pelestarian budaya. Motif-motif dasar tenun Muna terus dipertahankan meskipun telah mengalami komodifkasi motif. Samasili sebagai salah satu motif yang banyak mengalami komodifikasi oleh penenun dipadukan dengan beragai ragam motif seperti kupu-kupu, layang-layang, bahkan rangkaian motif lainnya. Artinya bahwa penenun memahami untuk tetap menjadikan tenun daerah tetap eksis ditengah perkembangan fashion dunia maka motif yang dihasilkan pun harus lebih menarik sesuai dengan perkembangan zaman. 
3. Terbuka dengan kemajuan. Adanya rangkaian motif yang dituangkan dalam motif dasar tenun Muna menggambarkan keterbukaan masyarakat Muna akan perkembangan trand fashion. Masyarakat tidak menutup diri dalam menghadapi perkembangan zaman namun menyerap dan menyesuikannya dengan kebudayaannya. Memadukan rangkaian motif dengan motif dasar Tenun Muna merupakan pilihan yang tepat bagi masyarakat penenun dalam menghadapi perkembangan fashion dan tetap mempertahankan identitas tenunan Muna.

4. Keberagaman. Melalui perpaduan warna dalam setiap motif tenun Muna yang dihasilkan menggambarkan keberagaman dalam sebuah karya. Tenun Muna dihasilkan oleh lebih dari satu warna dalam sebuah kainnya. Warnanya pun selalu bervariasi. Perpaduan warna yang menarik menjadikan motif tenun Muna semakin hidup.

Memaknai setiap simbol dari tenun Muna hasil komodifikasi tidak hanya dilihat dari aneka motif yang dihasilkan namun perpaduan warna yang semakin beragam dan menarik. Perpaduan aneka warna dalam setiap rangkaian motif tenun yang dihasilkan menggambarkan nilai kearifan lokal masyarakat dalam mengintegrasikan unsur budaya luar pada budaya asli pada selera fashion masyarakat.

\section{KESIMPULAN}

Perkembangan trand fashion ikut berdampak pada kemajuan aneka motif tenun Muna yang telah mengalami komodifikasi sehingga menjadikan lebih bernilai jual namun tidak meninggalkan motif yang telah ada secara turun temurun.

Perkembangan motif komodifkasi ini memiliki makna simbolik tersendiri yakni menggambarkan identitas daerah, pelestarian budaya, terbuka dengan kemajuan, keberagaman, serta menggambarkan nilai kearifan lokal dalam mengintegrasikan unsur budaya luar ke dalam perkembangan motif tenun Muna.

\section{DAFTAR PUSTAKA}

Arikunto, Suharsimi. 1998. Prosedur Penelitian : Suatu Pendekatan Prakte., Jakarta : Rineka Cipta.

Bungin, Burhan, 2015. Komunikasi Pariwisata : tourism communication, pemasaran dan brand destinasi. Jakarta : Kencana.

Emzir. 2010. Metodologi Penelitian Kualitatif : analisis data. Jakarta : PT. Raja Grafindo.

Ghony, Djunaidi dan Almanshur, Fauzan, 2012. Metode Penelitian Kualitatif. Yogjakarta : Ar-Ruzz Media

Miles, M.B dan Huberman, A.M., 1992, Analisis Data Kualitatif. UI Press, Jakarta.

Moeleong, Lexy J., 2000. Metodologi Penenlitian Kualitatit, Bandung: P.T. Remaja Rosdakarya.

Piliang, Yasraf Amir. 2015. Peran Strategis Seni dan Budaya dalam Membangun Kota Kreatif. Malang: Universitas Negeri Malang

Suhersono, Hery. 2006. Desain Bordir, Motif Batik. Jakarta : PT. Gramedia Pustaka Utama

Sibarani, Robert. 2012. Kearifan Lokal: Hakikat, Peran, dan Metode Tradisi Lisan. Jakarta : Asosiasi Tradisi Lisan. 


Jounal publiuho is licensed under a Creative Commons Attribution 4.0 International License, which permits
unrestricted use, distribution, and reproduction in any medium, provided the original work is properly cited.

Sudikan,Yuwana, Setya, 2013. Kearifan Budaya Lokal. Jawa Timur: Damar Ilmu

Utami, Agustin Dyah. Pemanfaatan Jejaring Social (facebook) sebagai Media Bisnis Online (studi kasus di batik solo 85). http //www.ijns.org/journal/index.php/seruni/article/view/603 ， diakses 23 agustus 2017.

Zebrina Pradjnaparamita, Tesis, Komodifikasi tas belanja bermerek: Motivasi dan Identitas Kaum Shopaholic Golongan Sosial Menengah Surabaya, (Program Magister Kajian Sastra dan Budaya, Fakultas Ilmu Budaya, Universitas Airlangga, 2012

zonasultra.com/tina-nur-alam-kampung-tenun-masalili-jadi-destinasi-wisata-sultra.html, diakses 23 agustus 2017 